\title{
Infective conjunctivitis and corneal scarring in three brothers with sex linked hypogammaglobulinaemia (Bruton's disease)
}

\author{
T T Hansel, D P O’Neill, M L Yee, J M Gibson, R A Thompson
}

\begin{abstract}
The ocular findings in three brothers with Bruton's disease are reported. All three boys had purulent conjunctivitis, but the two older brothers also developed marked corneal scarring with visual impairment. Haemophilus influenzae was cultured from conjunctival swabs; it was resistant to neomycin but sensitive to chloramphenicol. Tear analysis showed that the three subjects had normal levels of lysozyme but no detectable IgA.
\end{abstract}

In 1952 Lieutenant-Colonel Ogden C Bruton, an American paediatrician at the Walter Reed Army Hospital, described a boy with recurrent infections and absent serum immunoglobulins. ${ }^{12}$ Bruton's disease comprises sex linked hypogammaglobulinaemia, in which there is an inherited defect in B lymphocyte maturation, with consequent failure of antibody production. ${ }^{3-5}$ Diagnosis depends on the very low levels of all classes of immunoglobulins, the absence of circulating B cells, and a possible family history of affected male relatives.

Sex linked hypogammaglobulinaemia is a rare disease, accounting for a minority of cases of primary hypogammaglobulinaemia. Boys with the condition generally present with severe respiratory tract infections between 4 months and 2 years of age. The delay in onset of symptoms is due to transplacental passively acquired maternal antibody, which provides initial protection against micro-organisms. Infection is generally with bacteria such as Streptococcus pyogenes, Haemophilus influenzae, or Neisseria meningitidis, reflecting the role of antibody in opsonisation of encapsulated bacteria. In addition, patients with primary hypogammaglobulinaemia are susceptible to mycoplasma infections of the lungs, joints, and urinary tract, as well as chronic echovirus encephalitis/myositis. ${ }^{6-10}$

The treatment of Bruton's disease consists of lifelong immunoglobulin therapy, generally given as weekly intramuscular injections or three-weekly intravenous infusions. Infective episodes should be countered by aggressive antibiotic therapy, and postural drainage is beneficial for expulsion of purulent sputum.

The ocular complications are scantily documented. ${ }^{112}$ The Medical Research Council study of hypogammaglobulinaemia in the UK (195570) describes conjunctivitis and blepharitis, together with more serious recurrent corneal ulceration and keratitis, as occasional presenting features of antibody deficiency..$^{13}$ In a study of primary immunodeficiency diseases Franklin et al noted three cases of Bruton's disease with nonfollicular, non-purulent conjunctivitis associated with a superficial keratitis. ${ }^{14}$ From one of these cases Haemophilus influenzae type b was isolated.

\section{Case reports}

We consider three Caucasian brothers with Bruton's disease, the mother having the two older sons (aged 11 and 9 years) from a first marriage and the youngest son (aged 9 months) from a second marriage. The mother was unfortunate in that all three of her offspring were affected males. All three boys had marked hypogammaglobulinaemia involving all immunoglobulin classes, and lymphocyte surface marker analysis revealed absent mature $B$ cells.

The oldest boy presented at the age of $31 / 2$ years. He had a chronic cough and had developed a septic arthritis in the right knee. Staphylococcus was cultured from the joint, and serum antibody deficiency was detected (IgG $0.01 \mathrm{~g} / \mathrm{l}, \mathrm{IgA} 0.05 \mathrm{~g} / \mathrm{l}, \mathrm{IgM} 0.05 \mathrm{~g} / \mathrm{l}$ ). After initial treatment with intramuscular flucloxacillin and oral fucidin, followed by three-weekly replacement intravenous immunoglobulin, his joint and respiratory symptoms settled. The middle brother developed an effusion on his right knee at age 3 years and a perianal abscess at 6 years, but has otherwise remained well on immunglobulin therapy. The youngest brother began immunoglobulin therapy at age 6 months and remains healthy. On therapy all three brothers have maintained serum IgG levels at $>4 \mathrm{~g} / \mathrm{l}$.

The older two boys have had episodic purulent conjunctivitis with associated photophobia over a three-year period, while the youngest boy has had two episodes of mild conjunctivitis. Haemophilus influenzae was repeatedly cultured from conjunctival swabs. The two older brothers were initially treated with a course of chloramphenicol ointment for a fortnight, followed by neomycin ointment when required. Despite apparently slight conjunctival inflammation and discharge both older boys have developed marked corneal scars. The oldest boy has Immunology Department, East Birmingham Hospital Bordesley Green East,

Accepted for publication 12 September 1989 


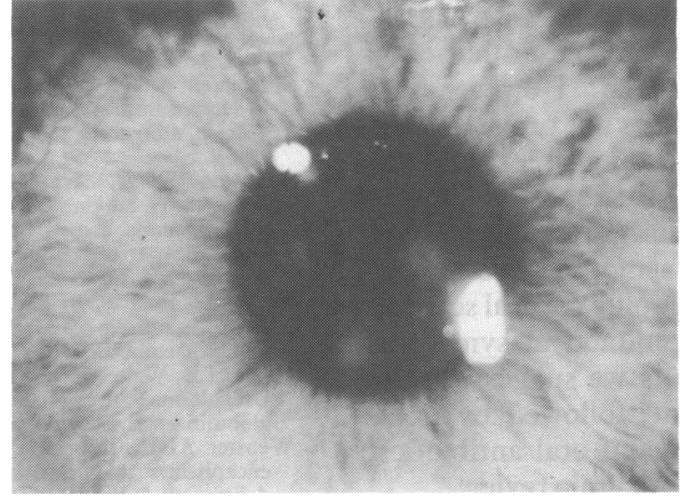

Figure 1: External photograph of cornea of oldest brother showing multiple central corneal opacities.

multiple, stromal corneal scars bilaterally, with vision at $6 / 12$ in each eye (Fig 1 ). The middle boy has a central corneal scar, with $6 / 36$ vision on the right, but no scars and $6 / 12$ vision on the left. The youngest brother has had two episodes of haemophilus conjunctivitis, but has no corneal scarring. All three brothers were treated with a one-month course of ocular chloramphenicol ointment, resulting in their conjunctivae being free from inflammation. The boys were then given a one-week course of oral trimethoprim together with ocular chloramphenicol.

\section{Material and methods}

Single radial immunodiffusion (Mancini technique) was used to measure immunoglobulins (IgG, IgA, and $\operatorname{IgM}$ ) in tears and saliva, while double diffusion (Ouchterlony technique) determined the presence or absence of secretory component in tears and saliva.

Quantitative estimation of lysozyme in tears was undertaken by measuring the lysis of Micrococcus lysodeikticus (Sigma). ${ }^{15}$ Human milk lysozyme (Sigma) was used as reference standard. M. lysodeikticus (10 mg) was dissolved in phosphate buffer $(\mathrm{pH} 6 \cdot 24,10 \mathrm{ml})$ and incubated at $4^{\circ} \mathrm{C}$ for 2 hours. This suspension $(0.5 \mathrm{ml})$ was added to agarose (Miles, $1.7 \%$ in phosphate buffer, $4.5 \mathrm{ml}$ boiled for $5 \mathrm{~min}$ and cooled to $56^{\circ} \mathrm{C}$ ). The mixture was poured on to glass plates and allowed to set, before wells were cut with a punch $(5 \mu$ l well volume). Samples $(5 \mu \mathrm{l})$ were applied to wells and incubated for 90 min at $37^{\circ} \mathrm{C}$. The diameter of the circle of lysis round wells was measured (the mean of two perpendicular graticule readings) in relation to the calibrant titration.

Conjunctival swabs were directly spread on blood agar and mycoplasma media. Blood agar plates were incubated aerobically and anaerobically. Conjunctival swabs were transported in chlamydia transport medium prior to culture in

TABLE I Levels of immunoglobulins (Ig), secretory component (SC), and lysozyme in tears from three brothers with $X$-linked hypogammaglobulinaemia

\begin{tabular}{llllll}
\hline Patient & IgG & IgA & IgM & SC & Lysozyme \\
\hline Oldest brother & $0.04(0.05)$ & ND $(0.54)$ & ND & Present & $2 \cdot 0(1 \cdot 0)$ \\
Middle brother & $0.03(0.04)$ & ND $(0.42)$ & ND & Present & $1.0(0.90)$ \\
Youngest brother & $0.02(0.02)$ & ND $(0 \cdot 17)$ & ND & Present & $0.65(0 \cdot 85)$
\end{tabular}

Levels are quoted as $\mathrm{g} / \mathrm{l}$, with values for an age and sex matched normal control (without ocular disease) given in brackets. ND= not detectable.
McCoy cells treated with cycloheximide, followed by modified Giemsa staining for typical chlamydia intracytoplasmic inclusion bodies. Haemophilus influenzae isolates were serotyped and biotyped by the Public Health Laboratory Service (PHLS) Haemophilus Reference Unit at the John Radcliffe Hospital, Oxford.

\section{Results}

The tear analysis is shown in Table 1 .

Initial conjunctival and nasopharyngeal swab cultures from all three boys yielded heavy growths of non-encapsulated Haemophilus influenzae of serotype II. Following treatment with $1 \%$ chloramphenicol ointment, a light growth of haemophilus remained in the conjunctiva of one boy, the other brothers having negative conjunctival cutures.

\section{Discussion}

Three brothers with Bruton's disease and infective conjunctivitis are presented, the two older boys developing corneal scarring with visual impairment. The conjunctivitis was clinically low grade, with slight purulent exudate and little erythema, but nevertheless corneal scars sufficient to impair vision developed.

Humoral antibacterial activity in normal tears is mainly due to lysozyme and IgA. When males with Bruton's disease receive intravenous immunoglobulin therapy, adequate levels of serum IgG can be achieved, but the serum levels of other immunoglobulin classes are unchanged. Hence patients' tears contain IgG but no detectable IgA, with a conjunctival IgA deficiency possibly contributing to their vulnerability to infective conjunctivitis. However, it must be stressed that patients with selective IgA deficiency are not at particular risk of bacterial conjunctivitis.

Non-encapsulated Haemophilus influenzae is present in the nasopharynx of most healthy children but normally constitutes less than $2 \%$ of the bacterial flora. Haemophilus may cause both upper and lower respiratory tract infections, as well as sporadic or epidemic conjunctivitis, disturbing immune mechanisms in the eye by production of an IgA protease. ${ }^{16}$ Therapy for haemophilus conjunctivitis in Bruton's disease is primarily by a topical antibiotic to which the bacterium is sensitive.

Following treatment with ocular chloramphenicol all three brothers had prompt resolution of their conjunctivitis. However, a light growth of haemophilus remained in one brother, and all three boys are being treated with ocular and oral antibiotics. This is in an effort to eradicate nasopharyngeal carriage, since haemophilus carried in the nasopharynx could ascend the lacrimal duct to reinfect the conjunctiva. Treatment of all three brothers was undertaken to minimise cross infection.

Neomycin-resistant chloramphenicol-sensitive haemophilus was cultured from the conjunctivae of all three brothers. This resistance could have developed after prolonged neomycin therapy, and may be due to drug destroying enzymes such as phosphotransferases and acetyltransferases. 
The presence of non-encapsulated strains of biotype II in all three boys suggests that cross infection may have occurred. However, the presence of haemophilus does not prove that the bacterium is directly responsible for the conjunctivitis and corneal scarring.

Our experience suggests that patients with antibody deficiency and haemophilus conjunctivitis may be at risk of developing corneal scarring despite relatively mild conjunctival symptoms and signs. In these patients we suggest careful microbiological assessment, followed by treatment with suitable ocular and oral antibiotics, combined with regular ophthalmic review.

We are grateful for the assistance of Dr J B Skelton and Dr M P E Slack of the PHIS Haemophilus Reference Unit at the John Radcliffe Hospital, Oxford.

1 Bruton OC. Agammaglobulinaemia. Pediatrics 1952; 9: 722-8. 2 Bruton OC. The discovery of agammaglobulinemia in man. In: Bergsma D, ed. Immune deficiency diseases in man. New York: National Foundation - March of Dimes, 1968: 2-6.

3 Asherson GL, Webster ADB. Diagnosis and treatment of immunodeficiency diseases. Oxford: Blackwell, 1980: 7.

4 Conley ME. B cells in patients with X-linked agammaglobulinemia. F Immunol 1985; 134: 3070-4.

5 Leickley FE, Buckley R. Variability in B cell maturation and differentiation in X-linked agammaglobulinaemia. Clin Exp Immunol 1986; 65: 90-9.

6 Taylor-Robinson D, Gumpel JL, Hill A, Swannel AJ. Isolation of Mycoplasma pneumoniae from the synovial fluid of a hypogammaglobulinaemic patient in a survey of patients with inflammatory polyarthritis. Ann Rheum Dis 1978; 37: $180-2$

7 Johnston CLW, Webster ADB, Taylor-Robinson D, Rapaport G, Hughes GRV. Primary late-onset hypogammaglobulinaemia associated with inflammatory polyarthritis and septic arthritis due to Mycoplasma pneumoniae (case report). Ann Rheum Dis 1983; 42: 108-10.

8 So AKL, Furr PM, Taylor-Robinson D, Webster ADB. Arthritis caused by Mycoplasma salivaria in hypogammaglobulinaemia. BrMed F 1983; 286: 762-3.

9 Vogler LB, Waites KB, Wright PF, Perrin JM, Cassell GH. Ureaplasma urealyticum polyarthritis in agammaglobulinaemia. Pedriatr Infect Dis 1985; 4: 687-91

10 Webster ADB, Tripp JH, Hayward AR, et al. Echovirus encephalitis and myositis in primary immunoglobulin encephalitis and myositis in primary

11 Schulkind ML, Little JM. Ocular manifestations of immunological deficiency disease (abstr). Proceedings of the Royal Society of Paediatric Research 1969. 4 .

12 Aronson SB, Elliott JH, Ocular inflammation. St Louis: Mosby, 1972: 28-33.

13 Hill LE. Hypogammaglobulinaemia in the UK. Med Res Council Spec Rep Ser 310. London: HMSO, 1971

14 Franklin RM, Winkelstein JA, Seto DSY. Conjunctivitis and keratoconjunctivitis associated with primary immunodeficiency diseases. Am $\mathcal{F}$ Ophthalmol 1977; 84: 563-6.

15 Gupta AK, Sarin GS, Lamba PA, D'Souza P. Immunoassay of tear lysozyme in acute adenovirus conjunctivitis. $\mathrm{Br} f$ Ophthalmol 1986; 70: 439-41.

16 Kilian M, Rheinholdt J, Mortensen SB, Sorensen $\mathrm{CH}$. Pertubation of mucosal immune defence mechanisms by bacterial IgA proteases. Clin Resp Physiol 1983; 19: 99-104. 